\title{
Adverse Selection In Group Insurance: The Virtues of Failing to Represent Voters
}

\author{
Robin Hanson \\ Department of Economics \\ George Mason University*
}

\begin{abstract}
Compared with non-union workers, union workers take more of their compensation in the form of insurance. This may be because unions choose democratically, and democratic choice mitigates adverse selection in group insurance. Relative to individually-purchased insurance, we show that group insurance chosen by an ideal profit-maximizing employer can be worse for every employee, while group insurance chosen democratically can be much better. The reason is that democracy can fail to represent the preferences of almost half the group.
\end{abstract}

JEL codes: J51, D82, G22

\section{Introduction}

Compared with non-union employees, union employees take much more of their compensation in the form of benefits, and mostly in various forms of insurance. This result persists after controlling for many confounding factors, and it helps explain both why most recent union contract disputes have been over health benefits, and why employee health coverage has declined over the last few decades. Many explanations of this union insurance emphasis have been suggested, but none of these explanations are completely satisfactory.

This paper suggests a new explanation of why unions favor insurance, an explanation based on the fact that unions tend to make internal choices democratically. The basic idea is that adverse selection is less of a problem under democratic choice. If true, this would make larger quantities of insurance cheaper for unions, and so induce unions to choose more insurance, all else equal.

In order to explore the possibility that democratic organizations such as unions suffer less from adverse selection in insurance, this paper considers a few simple models of adverse

*rhanson@gmu.edu http://hanson.gmu.edu 703-993-2326 FAX: 703-993-2323 MSN 1D3, Carow Hall, Fairfax VA 22030 
selection in group insurance. Specifically, we compare the insurance quantities chosen by individuals, by a profit-maximizing employer, and by an employee vote. To avoid distracting complications, we keep these models simple, without moral hazard, other clues or signals of risk, correlations between individual risks, or agency and administrative costs (Pauly, Percy, and Herring 1999). We also ignore the possibility of group self-insurance. Though this simplification seems appropriate for a first exploration, it must of course make us cautious about any conclusions we draw.

There are two additional reasons to analyze adverse selection in group insurance, other than to explain unions preferences for insurance. The first additional reason is that claims have long been made, and repeated often in standard health economics textbooks, that collective choice mitigates adverse selection in insurance (Phelps 1997, Folland, Goodman, and Stano 1997). No formal analysis has been offered in support of this claim; authors are usually satisfied to note that, because group risk is an average of individual risk, the variance of group risk is lower than the variance in individual risk. In fact, however, this argument is fallacious, as the degree of adverse selection does not depend on the variance of the risk distribution in standard models. The formal analysis presented in this paper can help us to re-evaluate this standard claim that group insurance mitigates adverse selection.

The second additional reason to consider adverse selection in group insurance is as a first step toward considering collective signaling in voting more generally. Voting models usually assume that elections directly determine outcomes, either by choosing policies or by choosing candidates who have previously committed to policies. In contrast, we might want to consider cases where people vote on a common signal to send to an audience, an audience who will then choose outcomes. It is often said, for example, that voting for a third party, "sends them a message," that repealing ineffective drug prohibition would "send the wrong message," and that national health insurance "shows solidarity." Since adverse selection in insurance remains a widely understood prototypical example of signaling, it seems an appropriate starting point for exploring voting over signals more generally.

This paper will first review what we know about how unions are compensated, and some of the explanations offered to explain that phenomena. We will then illustrate the main theoretical results in a very simple example, give an overview of the more general theoretical results, present those more general results, and finally illustrate those results again in a less simple example.

\section{Union Compensation}

Both unions are trying to renegotiate contracts that will boost medical benefits and cover soaring health-insurance costs. The two high-profile strikes follow dozens of recent union disputes in California and elsewhere over health benefits, an issue that may continue to plague contract negotiations coast-to-coast until the larger issue of health costs is addressed. (Wood 2003)

When compared with nonunion employees, unions seem to prefer certain kinds of benefits 
over wages. In the U.S. in 1999, 34.5\% of union worker compensation was in the form of nonwage benefits, versus $25.6 \%$ for nonunion workers (Richard M. Devens 2000). This preference for benefits is an important factor behind several recent policy trends. Most recent union contract disputes in the United States have been over health benefits; unions have even accepted reduced wages to maintain these increasingly expensive benefits. Also, declining unionization explains 20-35\% of the decline in employee and retiree health coverage over the last few decades (Woodbury and Bettinger 1991, Buchmueller, DiNardo, and Valletta 2002).

What kinds of benefits do unions prefer? U.S. union workers now have $25 \%$ higher wages, but nearly double the employer expenditures on health insurance (Buchmueller, DiNardo, and Valletta 2002). In 1989, union workers had $21 \%$ higher wages, but $78 \%$ higher benefits overall. In terms of wage equivalents, these higher benefits contained less sick leave, lower bonuses, $41 \%$ more paid leave (such as vacations and holidays), 111\% more health, life, and sickness insurance, $156 \%$ more in pensions, and $321 \%$ more premium and shift pay (Herman, Schwarz, and Kuhn 1992). Today $60 \%$ of union (vs. $44 \%$ of nonunion) workers have health benefits, a union effect that is most pronounced for workers in small establishments (Buchmueller, DiNardo, and Valletta 2002). Today $60 \%$ of union (vs. $46 \%$ of nonunion) workers have life insurance and $16 \%$ of union (vs. $11 \%$ of nonunion) workers have long-term care insurance. For pensions, the union versus nonunion percentages are $83 \%$ versus $45 \%$ for any benefits, $72 \%$ versus $15 \%$ for defined benefit plans, and $29 \%$ versus $40 \%$ for defined contribution plans (of Labor 2003).

Thus aside perhaps from premium and shift pay (comprising 14\% of discretionary union benefits), the benefit that unions seem to most prefer is insurance of various sorts (comprising $53 \%$ of discretionary union benefits). This includes life, accident, health, and long-term care insurance, and defined-benefit pensions, which have a large insurance component. Why do unions prefer insurance so?

Some have pointed to the fact that union workers tend to be wealthier and older (Herman, Schwarz, and Kuhn 1992). Studies which control for these factors, however, as well as for race, gender, industry, region, blue versus white collar tasks, and establishment size, still find that unions tend to prefer insurance. In fact, the union effects on pensions and other forms of insurance are estimated to be at least twice as strong as the next strongest effect, which is on vacations ${ }^{1}$ (Freeman 1981, Freeman and Medoff 1984). Another relevant clue is that when both union and non-union wages in Israel were set by collective agreements, people still joined unions for their non-wage benefits, such as health insurance (Haberfeld 1995).

Some other proposed explanations for the union effect on insurance are based on unions being relatively democratic organizations. Majority rule in the election of union officials is formally recognized by all national unions in the U.S., and actually practiced by most of them. While unions are often similar to one-party governments that repress dissent, there is certainly an important democratic component in union behavior overall (Rees 1989).

\footnotetext{
${ }^{1}$ Studies sometimes see large union effects on a few very small benefits. One study found a large effect on day care, while another found a large effect on vacation and holiday funds. These made up much less than $1 \%$ of compensation (Freeman and Medoff 1984).
} 
Some have argued that democratic unions are better informed about employee preferences. The argument is that employees are less afraid of revealing their preferences to union leaders, while employers tend to draw biased inferences from the entry and exit behavior of marginal workers, who are young and mobile and so less interested in insurance and pensions. And some evidence supporting this theory was found in surveys about employee satisfaction with their compensation mix (Freeman and Medoff 1984, Rees 1989). This union effect, however, has continued to persist undiminished for twenty years since the wide publication of this bias theory. It seems rather unlikely that employers still do not realize that in general employees want more insurance, relative to wages, than employers have been giving them.

Others have argued that since unions are relatively democratic organizations, median voter models are relevant, and the union effect on benefits can be understood in terms of systematic differences between median and average employee preferences (Booth 1995). The median employee might be older than the average employee, for example. A related theory is that without a union a "firm can to a considerable extent ignore the preferences of typically older less marketable workers ... who are effectively immobile" (Freeman and Medoff 1984).

The total compensation for each worker, however, is a separate issue from how large a contribution wages make to that total contribution. If a firm has the (often exercised) option of giving different classes of workers different benefit packages, then the relative influence of different classes should only tell us the relative compensation of those classes, and not how each classes' compensation is broken down into wages versus various benefits. For example, if only older workers prefer more insurance, then employers can give it to them only, with or without a union.

This paper offers a new explanation for why unions favor insurance, an explanation also based on union democratic choice, via a median voter model. The basic idea is that democratic choice mitigates adverse selection, making insurance cheaper for unions, and so inducing unions to buy more insurance.

Of course this cannot be a very plausible theory if adverse selection in insurance is not much of a problem even for nonunion employees. And it should be acknowledged that several recent studies have failed to find evidence of adverse selection in insurance. While adverse selection has been found where insurance companies are prohibited from using their knowledge of individual risk to set individual prices, such as in multi-plan group insurance (Cutler and Zeckhauser 1997), in the absence of this prohibition we often fail to observe the positive correlation between risk levels and insurance quantities predicted by simple adverse selection models. While such predicted correlations have been observed in markets for annuities (Finkelstein and Poterba 2002), recent studies have failed to find them in individual life insurance (Cawley and Philipson 1999) auto insurance (Chiappori and Salanie 2000, Hemenway 1990), and medical insurance (Cardon and Hendel 2001, Browne and Doerpinghaus 1993).

It turns out, however, that if customers have hidden information about both their risk preferences and their risk levels, adverse selection need not produce a correlation between insurance quantity and risk level (de Meza and Webb 2001). A more robust prediction of adverse selection is a correlation between insurance quantities purchased and subjective 


\begin{tabular}{r|cc|cc} 
& \multicolumn{2}{|c}{ Low Risk Type } & \multicolumn{2}{c}{ High Risk Type } \\
Insure Level & Cost & Benefit & Cost & Benefit \\
\hline Fully Insure & 40 & 50 & 80 & 100 \\
Half Insure & 20 & 27 & 40 & 54 \\
Quarter Insure & 10 & 14 & 20 & 28
\end{tabular}

Table 1: A Two-Type Insurance Example

consumer beliefs about risk levels, after controlling for risk-classifications done by insurance companies. And such correlations have been observed, for example in long-term care insurance, in the absence of an overall correlation between risk and insurance quantity (Finkelstein and McGarry 2003). It therefore remains possible that adverse selection is an important factor in insurance, and so analysis of such situations remain of interest.

\section{A Simple Example}

The basic intuitions behind the results of this paper can be illustrated in a simple example.

Let us consider some employees who face a future risk, a risk which they would like to be insured against. We will consider four possible levels of insurance for each employee: full insurance, half insurance, quarter insurance, and no insurance. And we will consider employees who are identical except that they are of two equally likely risk types, high risk and low risk. While each employee will know his own risk type, insurance companies will know only the overall type fractions and anything they can infer from individual behavior.

Each combination of employee type and insurance level is associated with two key parameters: an expected cost to insurers to pay off on claims, and a cash equivalent benefit to the employee to be so insured. The costs and benefits of three insurance levels, relative to no insurance, are given in table 1. We assume there are no wealth effects, so that these costs and benefits are independent of the price an employee pays for insurance.

Note that, compared with low risk employees, high risk employees have twice the risk of loss, and hence twice the costs and benefits of insurance. Also note that there are diminishing returns to insurance; the benefit of quarter insurance is $40 \%$ over its cost, but the benefit of full insurance is only $25 \%$ over its cost. If both types were fully insured, then since the two types are equally likely, employees would have an average welfare gain of 15 over no insurance (the average of a gain of $50-40=10$ for the low types and a gain of $100-80=20$ for the high types).

Each insurance companies will offer a menu of insurance policies from which customers can choose, with each insurance policy specifying an insurance level and a price. We assume that these are competitive risk-neutral insurance industries with zero administrative costs. Thus the price of each insurance policy must be equal to the expected cost from table 1, weighted by the fraction of employee types that are covered by this policy. We also assume pure strategy behavior; in equilibrium each buyer type chooses at most one insurance policy 
from the menus offered.

What happens if employees buy insurance individually, directly choosing from the menus of insurance policies? There are no pooling equilibria in this case, where both high and low risk employee types buy the same policy. This is because the average cost of the two types is always greater than the benefit to the low risk types. For example, if both types bought quarter insurance, the price would be 15 (the average of the costs of 10 and 20), but the low risk type only gets a benefit of 14 from that level of insurance.

There are separating equilibria, however, and the best equilibrium (i.e., the one with the highest average welfare gain) is where high risk types buy full insurance at a price of 80 , low risk types buy quarter insurance at a price of 10 , and a price of 40 is charged for half insurance which no one buys. ${ }^{2}$ There is no equilibrium where low risk types buy half insurance, because high risk types would defect. High risk types would rather buy half insurance at a low risk price than full insurance at a high risk price.

The average welfare gain in this separating equilibrium is 12 (an average of 4 for the low types and 20 for the high types). The difference between this and the average gain of 15 under full insurance for all types is the cost of 3 that is the problem of adverse selection in this example. Under adverse selection, low risk types under-insure in order to convince insurance companies that they are not high risk types.

Now let us consider a group of three random employees, whose types are not correlated. Since the two employee types are equally likely, there are now eight equally likely combinations of group types, which fall into four relevant classes. The majority-high class has the three combinations where two employees are high risk and one is low risk, and the majoritylow class has the three combinations where two employees are low risk and one is high risk. The all-high class has the one combination where all three employees are high risk, and the all-low class has the one combination where all are low risk.

What happens if an employer chooses a group insurance plan, again from a zero-administrativecost competitive insurance industry, on behalf of a group of three employees? Let us assume that this policy must be a uniform group policy, where each employee gets the same insurance level, and that this employer knows the actual risk type of each of his employees. Assume also that the employer must adjust each employee's wage to compensate for any changes in that employee's insurance policy, in order to keep that employee at or above some reservation utility level. This implies that this employer wants to maximize the sum of the benefits his three employees get from this insurance, minus the price he pays for that insurance.

From the point of view of an insurance company, there are four possible types of employers, corresponding to the four different classes of employee groups. Given a particular insurance level, each different employer type imposes a different expected cost on an insurance company who sells that policy to this employer. For example, given full insurance the average per employee cost of an all-high employer is 80 . An all-low employer costs 40 , a majority-high employer costs $662 / 3$, and a majority-low employer costs $531 / 3$.

\footnotetext{
${ }^{2} \mathrm{~A}$ price of 40 is charged because insurers expect that only high risk types would buy this policy. A description of an equilibrium must include the expectations of insurance companies about the relative proportion of types who would buy each policy, even if in equilibrium no types actually buy some policies.
} 
There is again no pooling equilibria here (for the same reason as before), and the best (partially) separating equilibrium has the all-high and majority-high employers buying full insurance, at a per-employee price of 70 , the all-low and majority-low employers buying quarter insurance, at a price of 12.5 , and half-insurance costs 35 , which no one buys. The average welfare gain over no insurance is 10.8125 , which is lower than the gain of 12 with individual insurance. Welfare is lower here because relative to individual insurance there is now variance in the insurance level for each individual risk type; high-risk employees now sometimes get less than full insurance, and low-risk types sometimes get full insurance.

What happens if a group of three employees votes on an insurance policy, after which they each pay the same price and get the same insurance level? Since all instances of each employee type should vote for the same policy, what matters here is which employee type is pivotal, i.e., in the majority. On average when high types are pivotal, $3 / 4$ of employees will be high types, and when low types are pivotal, $3 / 4$ of employees will be low types.

There are again no pooling equilibria (again for the same reason), and in the best separating equilibrium here pivotal high types buy full insurance at a per-employee price of 70 , pivotal low types buy half insurance at a price of 25 , and quarter-insurance costs 12.5 , which no one buys. The reason that half insurance is possible here, instead of the quarter insurance found in individual insurance, is that the price of full insurance is lower here. Because low types who find themselves in the minority are forced to get full insurance (at price so high that they would rather have no insurance), the price of full insurance is reduced. This makes pivotal high types less tempted to pretend to be pivotal low types in order to get a lower price. And this allows pivotal low types to buy more insurance.

The average welfare gain over no insurance is 13.125 here, which is higher than 12 with individual insurance. Welfare is higher because of the increase from quarter insurance to half insurance. This advantage outweighs the harm from the variance in the insurance level for each individual risk type.

In summary, in this simple example with two risk types and four insurance levels we see that there are never pooling equilibria, and in all separating equilibria the choosers who represent the highest risk employees choose full insurance. There are two main factors distinguishing the various equilibria. One factor is whether the alternative to full insurance is half insurance or quarter insurance. The other factor is how much variance there is in the insurance level for each risk type.

Group insurance chosen by an ideal employer has the worst of both factors, with quarter insurance and substantial variance in the insurance level for each risk type. Individual insurance does better, by eliminating the variance. Finally, voting by employees works a even better still, keeping half insurance and lowering the variance a little.

We will see that the advantages of voting on group insurance over individual insurance, and of individual insurance over an ideal employer group insurance, generalize. 


\section{Overview of General Results}

The remainder of this paper presents models which generalize the results described in the simple example above. We now review the main features and conclusions of those models.

We will take as our standard reference model a separating equilibrium among customers who buy individual insurance. That is, there are two possible states of the world, accident and no accident. Customers are identical except for their risk of suffering an accident, and there is a continuous distribution over this risk type. Insurance companies are competitive, risk-neutral, and have zero administrative costs, and so they will accept any insurance policy with a non-negative expected financial gain.

Formally, under individual insurance each customer, knowing his risk type, makes a single take-it-or-leave it offer to a single insurance company, who does not initially know the customer's risk type. Group insurance means that individual risk types are independent, and that the group makes a single take-it-or-leave offer about a single common insurance policy. We retain the standard focus on interim-Pareto dominant separating equilibria. ${ }^{3}$

We first consider group insurance choices made by a profit-maximizing employer who is fully informed about the risk types of his employees. This employer uses individual cash transfers to compensate employees for their personal like or dislike of the group insurance policy, in order to keep each individual at a reservation utility level. These reservation utility levels can vary across employees, so that employees can vary in their attractiveness to the employer.

We find that wealth effects complicate the analysis, because cash transfers can change the relative value of money in the accident versus no accident states. If we factor out such wealth effects, however, we find that employees must always be paid a non-negative (and usually a positive) compensation, if they are to be made at least as well off as they would be with individual insurance. There is thus no financial incentive for such an employer to offer group insurance.

The reason for this is that while the menu of prices and matching insurance quantities is the same for individual insurance and this group insurance, under group insurance each individual gets the same group policy, instead of his favorite policy chosen from this menu. The reason that the price menu is the same is that the support of the relevant distribution of types is the same. While the variance of types is lower, under group insurance this variance is irrelevant.

We next consider group insurance chosen via two forms of democracy, which give the same results. One form is a median voting rule, where everyone submits their favorite insurance policy and the median submission is implemented. The other form is a two candidate prospective voting model, where the two candidates both know the median type of the electorate, and then simultaneously commit to public positions.

We find that while democratically chosen insurance is not ex ante optimal, it can sub-

\footnotetext{
${ }^{3}$ While such equilibria are preferred by refinements such as intuitive equilibria (Cho and Kreps 1987), other refinements, such as undefeated equilibria (Mailath, Okuno-Fujiwara, and Poslewaite 1993), tend to prefer pooling equilibria, and there is admittedly little consensus on which is more realistic.
} 
stantially improve on individual insurance, because under majority rule democracy can fail to represent the opinions of up to half of the electorate. For example, when the group votes for the maximum insurance amount, the insurer knows that a bare majority of the group is of the worst possible type, but she knows nothing about the types of the rest of the group. Under democracy, the range of the risk distribution visible to an insurer is half of the range visible under individual insurance. This reduces adverse selection, because there aren't as many bad types for each good type to distinguish himself from.

These general results are illustrated in specific example with a continuum of risk types.

\section{Individual Insurance}

As a reference point for comparison, let us review the standard game of adverse-selection in individual insurance. This signaling game has two players, a risk-averse customer desiring insurance against a possible loss $L$, and a risk-neutral insurance company with zero administrative costs. (We denote the customer and insurer by male and female pronouns respectively.) If $x$ is the customer's loss when an accident occurs, and $y$ is his loss otherwise, then without insurance $x=L$ and $y=0$. With insurance, losses are $x, y \in(0, L)$. If the customer's probability of an accident is $p$, then the two player's expected payoffs are

$$
\begin{aligned}
\text { customer: } & U(x, y, t) \equiv p u(-x)+(1-p) u(-y)=p(t)(u(-x)+t u(-y)) \\
\text { insurer: } & V(x, y, t) \equiv p(x-L)+(1-p) y=p(t)((x-L)+t y)
\end{aligned}
$$

Here the right most expressions describe payoffs in terms of the customer's risk type $t$, where $p(t) \equiv 1 /(1+t)$ and $t=p^{-1}(p)=(1-p) / p$. Utility $u$ is assumed to be continuously differentiable, strictly increasing, and strictly concave.

The customer, knowing his risk type $t$, acts first by offering a contract $x(t), y(t)$. Then the insurer, knowing only a continuous prior distribution c.d.f. $F(t)$ on type $t$, and whatever she can infer from the customer's offer $(x, y)$, accepts or rejects that offer. Given rejection, $(x, y)=(L, 0)$.

The equilibria considered most often for such games are interim-Pareto-dominant maximallyseparating sequential equilibria ${ }^{4}$, which I call "standard." When we assume $F(t)$ has convex support $[\underline{t}, \bar{t}]$, with $\underline{t}<\bar{t}$, then a unique standard equilibrium exists with just barely accepted offers $x(t), y(t)$ satisfying $V(x(t), y(t), t)=0$. This implies

$$
y(t)=y^{*}(t, x(t))
$$

where the zero-profit fair insurance rate is $y^{*}(t, x) \equiv t(L-x)$.

Given an equilibrium dependence $x(t), y(t)$ of offers on type, each type $t$ chooses what type $t^{\prime}$ to pretend to be. That is, he chooses $t^{\prime}$ to maximize $U\left(x\left(t^{\prime}\right), y\left(t^{\prime}\right), t\right)$. Taking the first

\footnotetext{
${ }^{4}$ Such equilibria are chosen by refinements such as the intuitive criterion (Cho and Kreps 1987).
} 
order condition for this, and setting $t^{\prime}=t$, we get the local incentive compatibility condition for a separating equilibria, which is the differential equation

$$
\frac{u^{\prime}(-y(t)) y^{\prime}(t)}{u^{\prime}(-x(t)) x^{\prime}(t)}=-t
$$

Standard equilibria also satisfy $x^{\prime}(t)<0<y^{\prime}(t)$ and the boundary condition

$$
x(\bar{t})=x^{*}(\bar{t}, \bar{t})
$$

where we define a type $t$ customer's favorite insurance amount, given that he pays the fair insurance rate of a type $s$, as

$$
x^{*}(s, t) \equiv \operatorname{argmax}_{x} U\left(x, y^{*}(s, x), t\right)
$$

(This argmax is unique by the strict concavity of $u$.) Thus the highest risk type $\bar{t}$ gets his favorite level of insurance, in this case full insurance with $x=y$, and lower types are less than fully insured with $x>y$. The highest risk type suffers no adverse selection because there is no worse type that he is trying to distinguish himself from. If he cannot pool with lower risk types, he might as well get full insurance.

Let us denote this standard equilibrium, solving equations 1,2 and 3 , as $x_{1}(t), y_{1}(t)$. This same result occurs in an equilibrium of a competitive insurance market, where insurance companies make the first move by offering their menus of available policies, which customers then select among. Different results occur, however, when a monopolist insurer makes the first move.

Note that the equilibrium menu of choices $x_{1}(t), y_{1}(t)$ depends on the distribution $F$ only via the upper bound $\bar{t}$ of the support of $F$. No other features of the distribution $F$, such as its mean or variance, are relevant.

The basic equilibrium $x_{1}(t), y_{1}(t)$ is ex-ante worse than the ex-ante optimal pooling insurance, which would result from a contract between the customer and insurer made before the customer learned of his risk type $t$. (More precisely, the standard equilibrium is worse for customers on average, and the same for the insurer.) Under this optimal exante contract, all types would be fully insured as if they were of the average type $\hat{t}$, where $p(\hat{t}) \equiv E_{F}[p(t)]=\int p(t) d F(t)$. That is, for all $t$ we would have $x(t)=y(t)=\hat{x} \equiv x^{*}(\hat{t}, \hat{t})$.

\section{Group Insurance}

Let us now assume there is a group of $n$ customers. The risk type of this group is the $n$ dimensional vector $\vec{t} \equiv\left(t_{i}\right)_{i}$, and there is now a joint c.d.f. $J(\vec{t})$ with support $[\underline{t}, \vec{t}]^{n}$ over the risk types $t_{i}$ of each customer $i$. Assume that this joint $J$ is symmetric in the $t_{i}$, with individual marginals $F\left(t_{i}\right)$, and is common knowledge. Now instead of having each customer $i$ propose a contract $\left(x_{i}, y_{i}\right)$ to his insurer, the whole group will jointly propose a single contract $(x, y)$ to a single insurer, who will accept or reject that offer. Each group 
member will then have the same insurance policy $(x, y)$. The insurer remains risk-neutral with zero administrative costs, and this situation remains equivalent to a situation where in a competitive market each insurer offers a menu of policies from which the group can choose.

Risk neutral insurers are only interested in the average risk of the group $\bar{p}(\vec{t}) \equiv \sum_{i} p\left(t_{i}\right) / n$. Given an observed choice $(x, y)$, insurers thus react to the group's estimated type $s$, defined by $p(s) \equiv E_{J}[\bar{p}(\vec{t}) \mid \vec{t}$ picked $x, y]$. Given the low dimensional space of possible signals $(x, y)$, the most separation possible under group insurance is a semi-pooling equilibrium where the set of all possible group types $\vec{t}$ is partitioned into a one-dimensional continuum of sets $S$, such that every type $\vec{t} \in S$ picks the same $(x, y)$ in equilibrium. We can index these sets $S$ by their average risk type $s$, writing $S(s)$. Equilibrium offers can also be indexed as $x(s), y(s)$.

\section{Profit-Maximizing Employer}

Let us now consider a single ideal well-informed risk-averse profit-maximizing group employer. Each employee of this employer is a potential insurance customer. The employer knows the risk type $t_{i}$ of each employee, and hence knows the group risk type $\vec{t}$ of his firm. He is empowered to choose the group insurance offer $x(\vec{t}), y(\vec{t})$, and he can offer cash compensation $c_{i}$ to each employee. This employer desires to minimize a concave increasing function $f(c)$ of the total group compensation $c=\sum_{i} c_{i}$, and is constrained to give each employee at least a reservation utility level $\underline{U}_{i}$, so that $U\left(x-c_{i}, y-c_{i}, t_{i}\right) \geq \underline{U}_{i}$. Employees who do not get their reservation utility $\underline{U}_{i}$ will quit, greatly harming the employer.

Note that variations in the reservation utility level $\underline{U}_{i}$ can encode variations in the difficulty of attracting employee $i$, such as due to variations in age, experience, or education. The reservation utility level $\underline{U}_{i}$ can also encode variations in the quality of their outside insurance option. For example, employees who would quit unless their compensation package made them as well off as they would be with individual insurance would have $\underline{U}_{i}=U\left(x_{1}\left(t_{i}\right), y_{1}\left(t_{i}\right), t_{i}\right)$.

Given an equilibrium dependence $x(s), y(s)$ of offers on type, an employer of type $s$ chooses what type $s^{\prime}$ he will pretend to be. The employer's optimization of his offer choice has a Lagrangian

$$
f\left(\sum_{i} c_{i}\right)+\lambda_{i}\left(U\left(x(s)-c_{i}, y(s)-c_{i}, t_{i}\right)-\underline{U}_{i}\right)
$$

Substituting the first-order conditions for optimizing the compensations $c_{i}$ into the first-order conditions for optimizing $s^{\prime}$, and setting $s=s^{\prime}$, yields a new local incentive compatibility differential equation to replace equation 2 , namely

$$
\frac{u^{\prime}(-y(s)) y^{\prime}(s)}{u^{\prime}(-x(s)) x^{\prime}(s)}=-p^{-1}(\bar{p}(\vec{\gamma}))
$$

where $\vec{\gamma} \equiv\left(\gamma_{i}\right)_{i}$ and

$$
\gamma_{i} \equiv t_{i} \frac{u^{\prime}\left(c_{i}-y\right) / u^{\prime}(-y)}{u^{\prime}\left(c_{i}-x\right) / u^{\prime}(-x)}
$$


gives a wealth-adjusted risk type for each employee.

In general, compensation $c_{i}$ induces a wealth effect when $\gamma_{i} \neq t_{i}$, because in general the relative marginal value of money in the accident versus no accident states changes as a customer's wealth varies. This wealth effect should be small when reservation utilities $\underline{U}_{i}$ vary little or compensation is small $\left(\left|c_{i}\right| \ll L\right)$, but a non-zero wealth effect greatly complicates our analysis.

There are three conditions, however, where this wealth effect disappears, giving $\gamma_{i}=t_{i}$. It disappears at $x=y$, which is why the boundary condition, equation 3 , is unchanged from before. The wealth effect also disappears at equilibrium choices when zero compensation $\left(c_{i}=0\right)$ results because $\underline{U}_{i}=U\left(x_{2}(s), y_{2}(s), t_{i}\right)$ for $t_{i} \in S(s)$. Finally, the wealth effect disappears with exponential utility, where $u^{\prime}(a+b)=u^{\prime}(a) u^{\prime}(b)$.

Under employer-chosen group insurance, the standard equilibrium again satisfies the fair insurance equation 1 and the boundary condition 3, except these are now in terms of the group type $s$ instead of individual type $t$. That is, we have $y(s)=y^{*}(s, x(s))$ and $x(\bar{t})=$ $x^{*}(\bar{t}, \bar{t})$. Let us denote this new equilibrium, solving equations 1,3 , and 4 , as $x_{2}(s), y_{2}(s)$.

If we ignore wealth effects, group insurance offers no advantage over individual insurance.

Theorem 1 When there are no wealth effects, individual insurance and employer-chosen group insurance have the same standard equilibrium curves, with $x_{2}(s)=x_{1}(s)$. Employees with individual insurance reservation utility levels must be paid a non-negative, and almost always positive, compensation to accept employer-chosen group insurance.

(Proof in Appendix.)

With no wealth effects, the employer chooses contracts off the same equilibrium $x-y$ contract curve as with individual insurance. While the distribution over relevant types is not the same, i.e., $F(s) \neq \operatorname{Pr}_{J}[\bar{p}(\vec{t}) \leq s]$, this does not effect the equilibrium contract curve unless we use an equilibrium refinement which does not always select a maximally separating equilibrium. ${ }^{5}$ Since standard separating equilibria depend only on the worst type $\bar{t}$ in the type distribution, and not on other features of the distribution such as the variance, the lower variance of types under group insurance does not help.

In this model, employers have no reason to offer group insurance to their employees, who are at least as well off if they buy individual insurance. This conclusion could of course change if we allowed group insurance to have lower administrative costs (Pauly, Percy, and Herring 1999).

\footnotetext{
${ }^{5}$ I have not analyzed what particular equilibrium refinements are satisfied by these separating equilibria. It should be noted that for reasonable type distributions $F(t)$ and larger electorates, the distribution of $s$ should be highly concentrated, with very thin tails out to the extreme values. Thin tails should also appear in the distribution of $s$ in the next section on voting. Many have questioned the realism of separating equilibria in this sort of circumstance (Mailath, Okuno-Fujiwara, and Poslewaite 1993). Signaling game models have only been experimentally tested with two near-equal-weight types (Banks, Camerer, and Porter 1994).
} 


\section{Voting Among Group Members}

Let us now consider democratic choice over group insurance. This might, for example, describe union members who elect union leaders, leaders who had previously committed themselves to public positions on the compensation package that they will seek when negotiating with the employer. If the employer cared only about the total financial cost of the compensation package, union leaders would be free to choose how this total cost is broken into benefits of various sorts, including group insurance. Group insurance levels would then be determined by democratic choice among union members.

We will consider two specific mechanisms for democratic choice. We will here consider a simple direct democracy mechanism, and in the Appendix on Two Candidate Elections we consider a binary vote between two identical candidates who have each simultaneously and publicly committed to a particular group policy $x, y$. Both cases result in the same equilibrium, which is driven by the preferences of a pivotal voter, of median type $t_{m}=$ $\operatorname{median}_{i} t_{i}$, who chooses his favorite policy from the available options.

The democracy mechanism we consider now is a direct two-dimensional (2D) median vote, wherein each voter $i$ submits a pair $\left(x_{i}, y_{i}\right)$, and the offer made to the insurance company is given by the medians $x=\operatorname{median}_{i} x_{i}$ and $y=\operatorname{median}_{i} y_{i}$. In a standard equilibrium, and assuming $n$ odd for simplicity, each voter submits his favorite point $x\left(t_{i}\right), y\left(t_{i}\right)$ along an $x-y$ curve which separates accepted from rejected offers. Given this $x-y$ curve, it is a dominant strategy for each voter $i$ to submit his favorite point along this curve, regardless of what he knows about the types of other voters.

After all, points above the curve will be rejected, every point below the curve is dominated by some point on it, and along the curve preferences are single-peaked, so the usual onedimensional voting results apply (see Appendix on Equilibrium Details). Each voter of type $t_{i}$ effectively chooses a point in a box with opposing corners $x\left(t_{i-1}\right), y\left(t_{i-1}\right)$ and $x\left(t_{i+1}\right), y\left(t_{i+1}\right)$, for $t_{i-1} \leq t_{i} \leq t_{i+1}$, a choice which only matters if $t_{i}$ happens to be the median type $t_{m}$. The winning $(x, y)$ is thus the favorite point along this $x-y$ curve of the voter with the median type among the $n$ actual voters; the sample median type is pivotal.

The fact that the actual offer is the favorite, among those available in equilibrium, of the pivotal type $t$ implies that in a standard equilibrium the local incentive compatibility differential equation 2, expressed in terms of the pivotal type $t$, will be satisfied. We will thus index voting equilibria by the pivotal voter $t$, rather than by the group average type $s$ as we did with employer chosen group insurance.

The fair insurance and boundary conditions, equations 1 and 3, must be modified to account for the difference between the pivotal type $t$ and the average type $s$. The insurance company will infer what she can about the average risk $s$ from the group insurance offer $(x, y)$ chosen by the pivotal type $t$. That is, she will compute the dependence $s(t)$, given by $p(s(t))=E_{J}[\bar{p}(\vec{t}) \mid t$ pivotal]. Given this dependence $s(t)$, she will now make her accept or reject decision based on $V(x(t), y(t), s(t))$, rather than on the $V(x(t), y(t), t)$ used in individual insurance. We thus have a new fair insurance equation

$$
y(t)=y^{*}(s(t), x(t))
$$




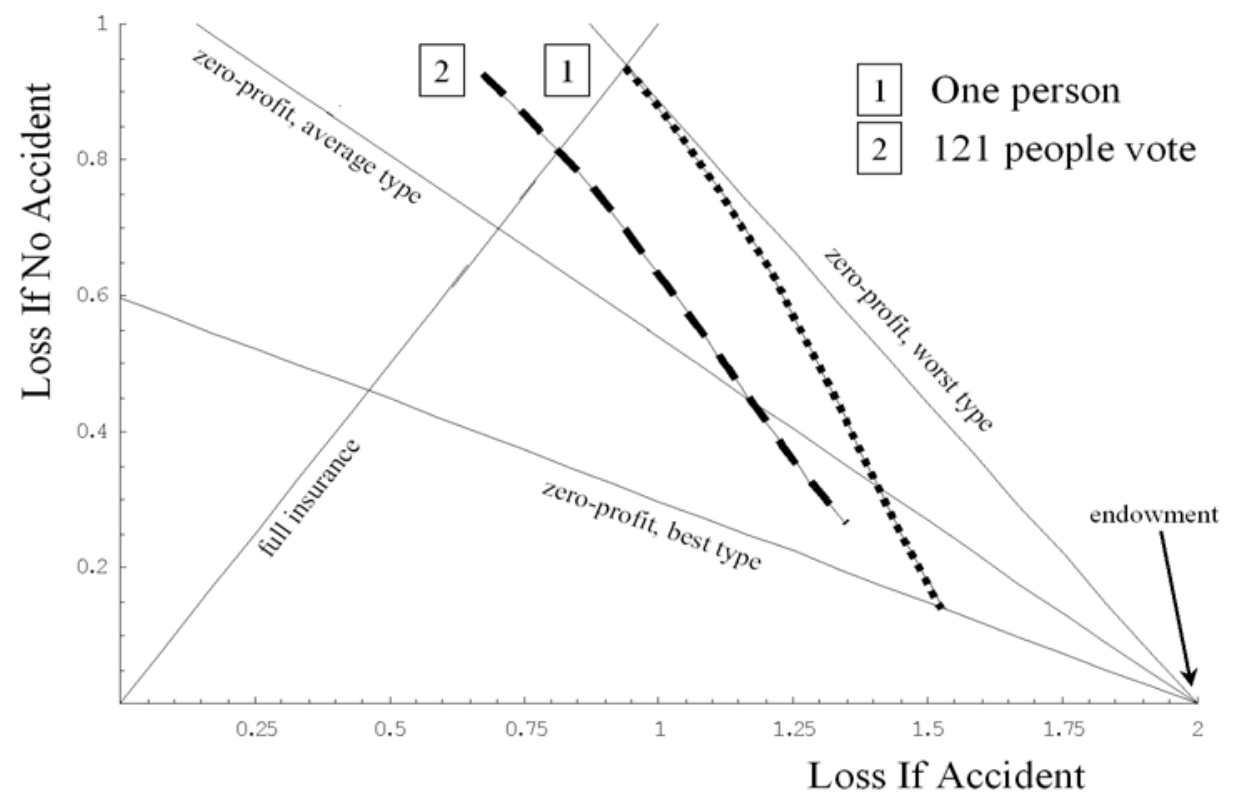

Figure 1: Comparing Equilibria in a Simple Example

that generalizes equation 1 , and a new boundary condition

$$
x(\bar{t})=x^{*}(s(\bar{t}), \bar{t}),
$$

that generalizes equation 3. Equations 2, 5, and 6 together specify the standard equilibrium of voting over group insurance, which we will label as $x_{3}(t), y_{3}(t)$.

To obtain a specific type dependence $s(t)$, let us assume that the group member types $t_{i}$ are i.i.d. (independently identically distributed), with $J(\vec{t})=\prod_{i} F\left(t_{i}\right)$. Given this, we have

$$
p(s(t))=\frac{1}{n} p(t)+\frac{n-1}{2 n}\left(E_{F}\left[p\left(t^{\prime}\right) \mid t^{\prime} \leq t\right]+E_{F}\left[p\left(t^{\prime}\right) \mid t^{\prime} \geq t\right]\right) .
$$

Given this type dependence, the range of relevant accident probabilities, which under individual insurance and employer chosen group insurance was $\Delta_{1}=p(\bar{t})-p(\underline{t})$, under democratically chosen group insurance becomes

$$
\Delta_{3}=p(s(\bar{t}))-p(s(\underline{t}))=\Delta_{1}(n+1) /(2 n) .
$$

Thus as $n \rightarrow \infty, \Delta_{3} \rightarrow \Delta_{1} / 2$; the relevant range under voting is only half as wide.

\section{An Example}

Figure 1 shows two numerically computed separating equilibria for exponential utility $u(x)=$ $-e^{-x}$ with an accident loss of $L=2$, and with the risk probability of types $p(t)$ distributed 
uniformly on $[.53, .77]$. For a uniform distribution on $p(t)$, equation ?? becomes

$$
p(s(t))=\frac{j+1}{2 n} p(t)+\left(1-\frac{j+1}{2 n}\right) p(\hat{t}) .
$$

For individual insurance the risk range is $.77-.53=.22$, while for large democracies $(n \rightarrow$ $\infty)$, this range is only half as large, at .11.

The straight lines in figure 1 are insurer indifference curves $V(x, y, t)=0$ for the mini-

mum, maximum, and average types $\underline{t}, \bar{t}, \hat{t}$. The two curves labeled square 1,2 are separating equilibria for two different cases.

Curve 1 describes $x_{1}, y_{1}$, the equilibrium for both individual insurance and also for profitmaximizing employer-chosen group insurance. The worst type $\bar{t}$ gets full insurance with $x=$ $y$, and better types rapidly get much less than full insurance. For large groups, the outcome is typically near where the insurer's indifference line for the average type $(V(x, y, \hat{t})=0)$ intersects curve 1. At this point, people get less that half of full insurance.

Curve 2 describes $x_{3}(t), y_{3}(t)$, the $2 \mathrm{D}$ median vote equilibrium, when there are 121 group members who all vote. When the pivotal voter is the worst possible type, insurers can infer that just over half of the group is the worst type, but can infer nothing about the rest of the group. Since the average inferred type in this case is better than that of the pivotal voter, the pivotal voter faces relatively cheap insurance, and chooses to over-insure. Thus the curve begins with $y>x$. Adverse selection quickly makes better groups under-insure, however, and for large groups most outcomes are likely to be near where the insurer's indifference line for the average type line intersects curve 2 .

This voting equilibria does usually result in substantially more insurance than with employer-chosen group insurance. This improvement can be thought of as due to the fact that the curve starts at a better point for the worse type, since knowing that the worse type is the median type tells insurers nothing about almost half of the electorate.

\section{Conclusion}

Compared to non-union employees, union members take a much larger fraction of their compensation in the form of various kinds of insurance. This tendency persists after controlling for many relevant factors, and the explanations offered to date are not very satisfying. This paper has explored the possibility that unions buy more insurance because insurance is cheaper for unions, because democratic choice mitigates adverse selection.

This paper has considered some simple models of adverse selection in group insurance, comparing individually-chosen insurance to employer-chosen and democratically-chosen group insurance. This analysis has been conducted not only because it may help explain union preferences for insurance, but also because it seems a reasonable first step in studying voting over collective signals more generally, and because it can help us evaluate widespread claims that group insurance mitigates adverse selection problems, claims that have not yet been subject to theoretical analysis. 
We found that employer-chosen group insurance can be worse than individual insurance, because it adds a one-size-fits-all problem onto the usual adverse selection problem. (We ignore any administrative cost advantages of group insurance, and the reduction in variance in group risk turns out to be irrelevant to the standard equilibrium we consider.) In contrast, democratically chosen group insurance was found to improve on individual insurance, mainly because democracy can fail to represent the interests of up to half of the electorate. The types of unrepresented voters are not signaled to insurers, hence reducing the signaling problem.

We showed these results in the context of two examples, one with two risk types and four insurance levels, and another with a continuum of risk types and insurance levels. We also proved some general results regarding employer-chosen insurance in the absence of wealth effects.

If confirmed, the hypothesis that insurance is cheaper for unions because democratic choice mitigates adverse selection would offer both an explanation of current union practice and an argument in favor of labor unions. This would also suggest explanations and arguments for other democratically-organized groups, such as homeowners associations and churches, who buy insurance for their members. This argument would be far from decisive of course; this benefit would have be weighed against all the other costs and benefits of such organizations.

Finally, the models in this paper suggest more generally, though again only weakly, that there may be substantial signaling advantages, to be weighed against relevant disadvantages, of political systems where decision-makers are not very responsive to voters. This may be relevant, for example, to the efficiency of judge-made law and unresponsive administrative agencies.

\section{Proof Appendix}

Proof of Theorem 1: Without wealth effects, $\gamma_{i}=t_{i}$ for all $\vec{t} \in S(s)$. In this case the right-hand side of equation 4 is $-p^{-1}(\bar{p}(\vec{t}))$. Thus all the types $\vec{t}$ who choose this $x(s), y(s)$ have the same value of $\bar{p}(\vec{t})$, and so by $p(s)=E_{J}[\bar{p}(\vec{t}) \mid \vec{t}$ picked $x, y]$ we have $p(s)=\bar{p}(\vec{t})$. Thus the right side of equation 4 is $-s$, making this equation the same as equation 2 with $s$ substituted for $t$. Since $x_{1}, y_{1}$ is the solution to equations 1,2 , and 3 , and $x_{2}, y_{2}$ is the solution to equations 1,3 , and 4 , then if equations 4 and 2 are the same, we must have $x_{2}(s)=x_{1}(s)$ and $y_{2}(s)=y_{1}(s)$.

Under individual insurance, each customer gets his favorite point $t \in[\underline{t}, \bar{t}]$ along the curve $x_{1}(t), y_{1}(t)$. Without wealth effects this also describes an employee with compensation $c_{i}$, since such an employee's favorite point on this curve is then independent of compensation $c_{i}$. If an employee with an individual insurance reservation utility level $\underline{U}_{i}=U\left(x_{1}\left(t_{i}\right), y_{1}\left(t_{i}\right), t_{i}\right)$ happens to also be of type $t_{i}=s$, then the group insurance plan $x_{2}(s), y_{2}(s)$ will be exactly the same as his individual plan $x_{1}\left(t_{i}\right), y_{1}\left(t_{i}\right)$ would be, and so zero compensation $\left(c_{i}=0\right)$ will be required to keep him at or above his reservation level. An employee of any other type $t_{i} \neq s$, however, would be worse off with zero compensation and the group insurance 
plan, since then $U\left(x_{1}(s), y_{1}(s), t_{i}\right)<U\left(x_{1}\left(t_{i}\right), y_{1}\left(t_{i}\right), t_{i}\right)=\underline{U}_{i}$. He will thus require a positive compensation $c_{i}$ to accept the group plan. QED.

\section{Appendix on Equilibrium Details}

There are many possible insurer belief profiles which can support the equilibrium dependence $x_{1}(t)$. One example is where insurer beliefs result in these insurer expectations:

$$
\mathrm{E}[p(t) \mid \text { offer }(X, Y)]=\left\{\begin{array}{lll}
p(\bar{t}) & \text { if } \quad X<x_{1}(\bar{t}) \\
p\left(x_{1}^{-1}(X)\right) & \text { if } \quad X \in\left[x_{1}(\bar{t}), x_{1}(\underline{t})\right] \\
p(\underline{t}) & \text { if } \quad X>x_{1}(\underline{t})
\end{array}\right.
$$

If we temporarily re-express utility as $U(x, y, t)=\tilde{U}\left(u_{x}, u_{y}, t\right)=p(t)\left(t u_{x}+u_{y}\right)$, where $u_{x}=u(-x), u_{y}=u(-y)$, then for all $t \in R, \tilde{U}$ everywhere satisfies the standard singlecrossing condition in terms of $u_{x}, u_{y}$, and $t$, since

$$
\frac{d}{d t}\left(\frac{\partial \tilde{U}}{\partial u_{x}} / \frac{\partial \tilde{U}}{\partial u_{y}}\right)=1 .
$$

Thus the local incentive compatibility equation (equation 2) implies global incentive compatibility, and a solution to this differential equation exists. (See (Fudenberg and Tilole 1991), chapter 7.) This solution is unique given a particular boundary condition.

Note that the single-crossing condition of equation 8 also guarantees that insurer preferences will be single-peaked along any separating equilibrium $x-y$ curve satisfying a local incentive compatibility equation such as equation 2 . After all, if preferences were not singlepeaked, at some point the local incentive compatibility equation would have to be satisfied for two distinct points for the same type.

\section{Appendix on Two Candidate Elections}

We have previously shown that a 2D median vote form of direct democracy results in $x_{3}(t), y_{3}(t)$, the solution of equations 2,5 , and 6 . We now show that these same outcomes result from a simple two candidate prospective voting rule. Two identical candidates must each simultaneously and publicly committed to a particular group policy $x, y$ which they will implement if elected. Assume that both candidates know the median type $t_{m}$ of the electorate, and for simplicity that insurers only observe the policy of the winning candidate.

If candidates were constrained to pick positions along the $x_{3}(t), y_{3}(t)$ curve, the standard median voter results would clearly apply. After all, we know that voter preferences are single-peaked along this curve, and insurers would accept such offers since the election result would only tell them what is the median type $t_{m}$. Candidates will also stay on the $x_{3}(t), y_{3}(t)$ curve if they are free to pick positions in the entire $x-y$ plane, because no majority prefers 
any other point to the median type's favorite point $x_{3}\left(t_{m}\right), y_{3}\left(t_{m}\right)$ along the $x-y$ curve which separates accepted from rejected offers.

First, no majority prefers offers which would be rejected. After all, the worst type $\underline{t}$ prefers $x_{3}(\underline{t}), y_{3}(\underline{t})$ to the rejection point $(L, 0)$, and by single-crossing all other types have even stronger preferences that way. Also, by the monotonicity of $u$ all types also dislike any distinct point $(x, y)$ for which $x \geq x(t)$ and $y \geq y(t)$.

Finally, for any point $(x, y)$ for which $x<x(t)$ and $y>y(t)$, by single-crossing the type who is just indifferent between these two points must be higher than the median type, and the types who strictly prefer the offer $(x, y)$ must be even higher still. But then this set of types could not be a majority. A similar argument applies for $(x, y)$ for which $x>x(t)$ and $y<y(t)$.

\section{References}

Banks, J., C. Camerer, and D. Porter (1994): "An Experimental Analysis of Nash Refinements in Signaling Games," Games and Economic Behavior, 6, 1-31.

Booth, A. L. (1995): The Economics of Trade Unions. Cambridge University Press, Cambridge.

Browne, M. J., and H. I. Doerpinghaus (1993): "Information Asymmetries and Adverse Selection in the Market for Individual Medical Expense Insurance," Journal of Risk and Insurance, 60(2), 300-312.

Buchmueller, T. C., J. DiNardo, and R. G. Valletta (2002): "Union Effects on Health Insurance Provisions and Coverage in the United States," Industrial and Labor Relations Review, 55(4), 610-27.

Cardon, J. H., And I. Hendel (2001): "Asymmetric Information in Health Insurance: Evidence from the National Medical Expenditure Survey," RAND Journal of Economics, $32(3), 408-27$.

Cawley, J., and T. Philipson (1999): "An Empirical Examination of Information Barriers to Trade in Insurance," American Economic Review, 89(4), 827-46.

Chiappori, P.-A., And B. Salanie (2000): "Testing for Asymmetric Information in Insurance Markets," Journal of Political Economy, 108(1), 56-78.

Cho, I.-K., And D. Kreps (1987): "Signalling Games and Stable Equilibria," Quarterly Journal of Economics, 102, 179-222.

Cresta, J.-P., And J.-J. Laffont (1987): "Incentive Compatibility of Insurance Contracts and The Value of Information," Journal of Risk and Insurance, 54, 520-540. 
Cutler, D. M., and R. J. Zeckhauser (1997): “Adverse Selection in Health Insurance," Discussion Paper 6107, National Bureau of Economic Research.

DE MezA, D., And D. C. WebB (2001): "Advantageous Selection in Insurance Markets," RAND Journal of Economics, 32(2), 249-62.

Epple, D., and R. E. Romano (1996): "Public Provision of Private Goods," Journal of Political Economy, 104(1), 57-84.

Finkelstein, A., And K. MCGarry (2003): "Private Information and its Effect on Market Equilibrium: New Evidence From Long-Term Care Insurance," Discussion Paper 9957, National Bureau of Economic Research.

Finkelstein, A., And J. Poterba (2002): "Selection Effects in the Market for Individual Annuities: Evidence from the United Kingdom," Economic Journal, 112, 28-50.

Folland, S., A. Goodman, and M. Stano (1997): The Economics of Health and Health Care. Prentice Hall, Upper Saddle River, New Jersey, 2nd edn.

Freeman, R. B. (1981): "Effect of Unionism on Fringe Benefits," Industrial and Labor Relations Review, 34(4), 489-509.

Freeman, R. B., and J. L. Medoff (1984): What Do Unions Do? Basic Books, New York.

Fudenberg, D., And J. Tilole (1991): Game Theory. MIT Press, Cambridge MA.

Goldstein, G. S., And M. V. Pauly (1976): "Group Insurance as a Local Public Good," in The Role of Health Insurance in the Health Services Market. National Bureau of Economic Research.

Gouveia, M. (1997): "Majority Rule and Public Provision of Health Care," Public Choice, $93(3,4), 221-44$.

Haberfeld, Y. (1995): "Why Do Workers Join Unions? The Case of Israel," Industrial and Labor Relations Review, 48(4), 656-670.

Hemenway, D. (1990): "Propitious Selection," The Quarterly Journal of Economics, 105(4), 1063-1069.

Herman, E. E., J. L. Schwarz, and A. Kuhn (1992): Collective Bargaining and Labor Relations. Prentice Hall, Englewood Cliffs, New Jersey, third edn.

Mailath, G., M. Okuno-Fujiwara, and A. Poslewaite (1993): "Belief-Based Refinements in Signaling Games," Journal of Economic Theory, 60, 241-276.

Maskin, E., And J. Tirole (1990): "The principal-agent relationship with an informed principal. I Private Values," Econometrica, 58, 379-410. 
Meier, K. J. (1991): "The Politics of Insurance Regulation," Journal of Risk and Insurance, $58(4)$.

of Labor, U. D. (2003): "Employee Benefits in Private Industry, 2003," Discussion Paper 03-489, Bureau of Labor Statistics.

Pauly, M., A. Percy, and B. Herring (1999): "Individual Versus Job-Based Health Insurance: Weighing the Pros and Cons," Health Affairs, 18(6), 28-44.

Phelps, C. E. (1997): Health Economics. Addison-Wesley, Menlo Park, California, 2nd edn.

ReEs, A. (1989): Economics of Trade Unions. University of Chicago Press, Chicago, third edn.

Richard M. Devens, J. (2000): "Benefits bigger piece of union compensation," Monthly Labor Review, The Editor's Desk, http://www.bls.gov/opub/ted/2000/May/wk5/art01.htm.

Summers, L. H. (1989): "Some Simple Economics of Mandated Benefits," American Economic Review, 79(2), 177-83.

Wood, D. B. (2003): "More Workers Strike Over Healthcare Benefits," Christian Science Monitor.

Woodbury, S., and D. Bettinger (1991): "The Decline of Fringe Benefit Coverage in the 1980s," in Structural Changes in US Labor Markets: Causes and Consequences, ed. by R. W. Eberts, and E. L. Groshen, pp. 105-138. ME Sharpe, New York. 